\title{
Autoimmune atrophic gastritis presenting as myelopathy in a young patient
}

Mielopatia como apresentação de gastrite atrófica autoimune em um doente jovem

\author{
Ana Teresa Carvalho Postal', Sara França1, Dias Costa², Joana Guimarães ${ }^{1,3}$
}

\author{
${ }^{1}$ Neurology Department, Vila Nova Gaia/Espinho Hospital Center, Vila Nova de Gaia, Portugal; \\ ${ }^{2}$ Neuroradiology Department, São João Hospital Center, Oporto, Portugal; \\ ${ }^{3}$ Faculty of Medicine, University of Oporto, São João Hospital Center, Oporto, Portugal. \\ Correspondence: Ana Teresa Carvalho Postal; Alameda Prof. Hernâni Monteiro 4200-319; Oporto- Portugal; E-mail: a.teresa.carvalho@gmail.com \\ Conflict of interest: There is no conflict of interest to declare. \\ Received 30 January 2012; Received in final form 02 March 2012; Accepted 09 March 2012.
}

Non-traumatic causes of extensive hyperintense spinal cord signal on T2-weighted images include a wide-ranging variety processes, such as tumors and associated disorders, inflammation, infection, vasculopathy, congenital disorders or metabolic diseases [namely vitamin $\mathrm{B}_{12}$ deficiency $\left.(\mathrm{VBD})\right]$.

We present a 36 year-old male patient complaining from progressive sensory loss on both hands and sensation of chest and abdominal tightness, lasting for five weeks. Neurological examination revealed a mild tetraparesis, glove and sock hyposthesia, C2 to T11 sensory impairment, vibratory anesthesia and proprioceptive errors of lower limbs. Cerebellar tests were normal. Romberg, Babinski and Lhermitte signs were absent. Laboratory tests revealed $\mathrm{Hb} 14.3 \mathrm{~g} / \mathrm{dL}$, mean corpuscular volume $104 \mathrm{fL}$. Renal and hepatic functions, iron study, copper levels and angiotensin conversion enzyme, and folic acid were normal. Vitamin B12 level was $<82$ pg/mL (189-883 pg/mL). Serum immunology, virology and bacteriology were negative. CSF study and brain MRI were unremarkable. Cervical spine MRI showed hyperintense spinal cord signal on T2weighted images affecting mainly dorsal, but also lateral, columns between medulla oblongata and T11 levels, with subtle contrast enhancement (Fig A-C). Basing on clinical and laboratory examinations, the patient was evaluated for extensive myelopathy due to VBD, and it was performed an upper gastrointestinal examination which revealed an atrophic mucosa; histological examination showed chronic atrophic gastritis and intestinal metaplasia, excluding Helicobacter pylori infection. Anti-parietal cells were negative, but anti-intrinsic factor antibodies were positive. Treatment was performed with IM cyanocobalamin replacement, 1,000 $\mu \mathrm{g}$ IM daily for a week, then weekly for four weeks and monthly afterwards. Three months later, there was a significant clinical recover, only remaining hypoesthesia of hand fingers. MRI performed at this time showed an exuberant improvement (Fig D).

Subacute combined degeneration (SCD) refers to degeneration of the posterior and sometimes lateral columns of the
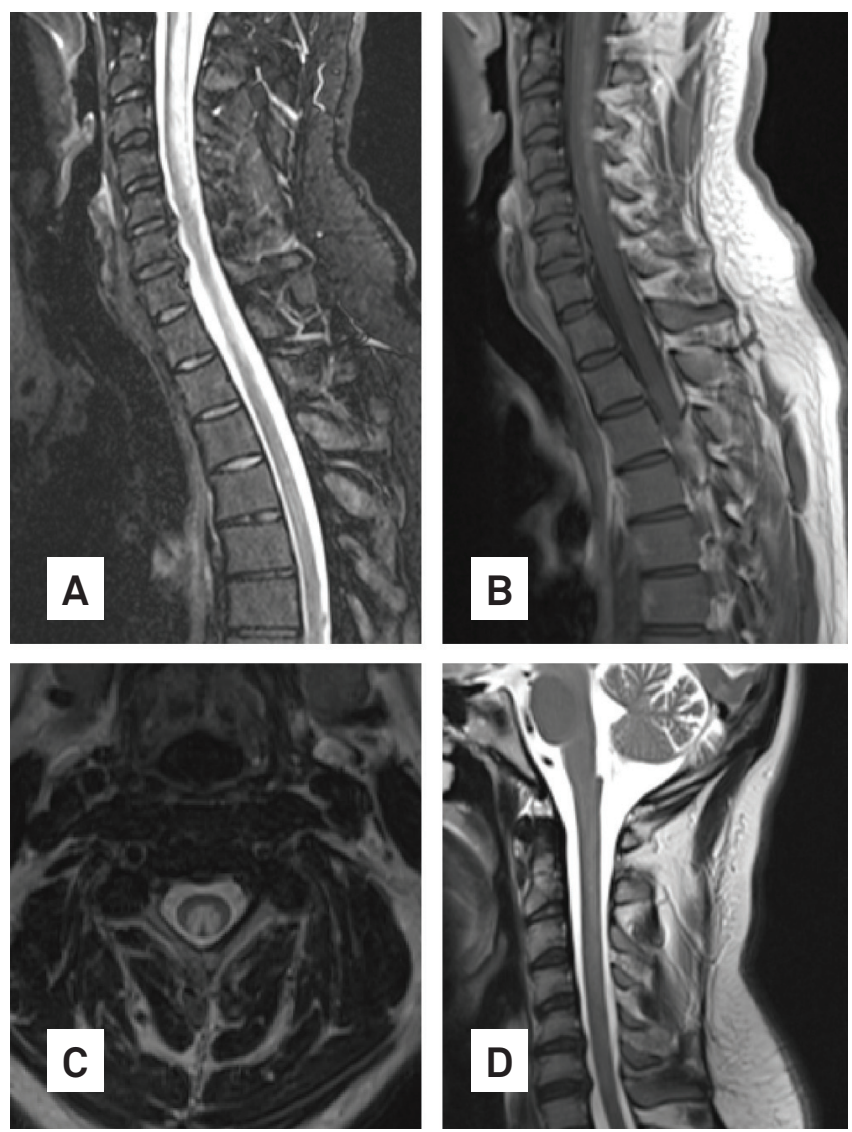

Fig. Spinal cord MRI: (A) extensive swelling of spinal cord, caused by vacuolization of myelin; (B) subtle contrast enhancement of posterior column; (C) cross-section images of spinal cord MRI: bilateral paired areas of hyperintensity affecting dorsal and lateral columns; (D) three months after treatment: significant improvement of lesions, with mild and no gadolinium enhancer T2 hyperintensity extending from bulbomedular transition until C7 without spinal cord expansion.

spinal cord usually as a result of VBD, which effects may not be appreciated until several years, since there is a significant body store of vitamin $\mathrm{B}_{12}^{1,2}$. Its absorption occurs via the ileal microvilli after binding to the intrinsic factor ${ }^{3}$, and malabsorption 
provoked by gastric atrophy is the commonest cause of VBD. Autoimmune atrophic gastritis (AAG) is a special type of gastric atrophy characterized by serum antibodies antiparietal cells and/or anti-intrinsic factor. AAG was an unexpected diagnosis since it is a relatively rare disease and the peak age of onset is 60 years, with only $10 \%$ of patients being $<40$ years of age. Myelopathy alone as clinical presentation is also a rare situation, occurring in about $12 \%$ of patients ${ }^{1}$. Concerning on imagiological findings, there was not only the involvement of the posterior column, but also of the lateral column, rarely involved in $\mathrm{SCD}^{4}$. Attention must be taken since AAG increases the risk of gastric carcinoid tumors and gastric carcinoma.

So, although being a rare condition, mainly in that age group, AAG needs to be remembered concerning its treatable nature and malignant potential that requires an appropriate follow-up.

\section{References}

1. Healton EB, Savage DG, Brust JC, Garrett TJ, Lindenbaum J. Neurologic aspects of cobalamin deficiency. Medicine (Baltimore) 1991;70: 229-245.

2. Stabler SP, Allen RH, Savage DG, Lindenbaum J. Clinical spectrum and diagnosis of cobalamin deficiency. Blood 1990;76:871-881.
3.

Shevell MI, Rosenblatt DS. The neurology of cobalamin. Can J Neurol Sci 1992;19:472-486.

4. Hughes JT. Pathology of the spinal cord. 2nd ed. In: Bennington J (Ed). Major problems in pathology. Vol 6. Philadelphia, Pa: Saunders, 1978;192-196. 